Fahad M.S. Arattu Thodika, Mahesh Nanjundappa, Theodore Dassios, Aaron Bell and Anne Greenough*

\title{
Pulmonary hypertension in infants with bronchopulmonary dysplasia: risk factors, mortality and duration of hospitalisation
}

https://doi.org/10.1515/.jpm-2021-0366

Received July 26, 2021; accepted November 16, 2021; published online December 1, 2021

\section{Abstract}

Objectives: Pulmonary hypertension $(\mathrm{PH})$ is a complication of bronchopulmonary dysplasia (BPD) and associated with increased mortality and morbidity. Our aim was to identify, in infants with BPD, the effect of $\mathrm{PH}$ on health-care utilisation and health related cost of care.

Methods: An electronic data recording system was used to identify infants $\leq 32$ weeks of gestation who developed BPD. $\mathrm{PH}$ was classified as early ( $\leq 28$ days after birth) or late (>28 days after birth).

Results: In the study period, 182 infants developed BPD; 22 (12.1\%) developed late PH. Development of late PH was associated with a lower gestational age [24.6 (23.9-26.9) weeks, $\mathrm{p}=0.001$ ] and a greater need for positive pressure ventilation on day 28 after birth (100\%) compared to infants without late $\mathrm{PH}$ (51.9\%) (odds ratio (OR) 19.5, 95\% CI: 2.6-148), p<0.001. Late PH was associated with increased mortality (36.4\%) compared those who did not develop late $\mathrm{PH}(1.9 \%)$ after adjusting for gestational age and

*Corresponding author: Professor Anne Greenough, Department of Women and Children's Health, School of Life Course Sciences, Faculty of Life Sciences and Medicine, King's College London, London, UK; Asthma UK Centre for Allergic Mechanisms in Asthma, King's College London, London, UK; and NIHR Biomedical Research Centre based at Guy's and St Thomas' NHS Foundation Trust and King's College London, London, UK, Phone: 0203299 3037,

E-mail: anne.greenough@kcl.ac.uk

Fahad M.S. Arattu Thodika, Department of Women and Children's Health, School of Life Course Sciences, Faculty of Life Sciences and Medicine, King's College London, London, UK. https://orcid.org/0000-0002-8791-3122

Mahesh Nanjundappa, Neonatal Intensive Care Centre, King's College Hospital NHS Foundation Trust, London, UK

Theodore Dassios, Department of Women and Children's Health, School of Life Course Sciences, Faculty of Life Sciences and Medicine, King's College London, London, UK; and Neonatal Intensive Care Centre, King's College Hospital NHS Foundation Trust, London, UK Aaron Bell, Department of Paediatric Cardiology, Evelina Children's Hospital, Guy's and St Thomas' NHS Foundation Trust, London, UK ventilation duration (OR: 26.9, 95\% CI: 3.8-189.4), $\mathrm{p}<0.001$. In infants who survived to discharge, late $\mathrm{PH}$ development was associated with a prolonged duration of stay [147 (118-189) days] compared to the infants that did not develop late PH [109 (85-149) days] ( $\mathrm{p}=0.03$ after adjusting for gestational age). Infants who had late $\mathrm{PH}$ had a higher cost of stay compared to infants with BPD who did not develop late PH (median £113,494 vs. €78,677, p=0.016 after adjusting for gestational age).

Conclusions: Development of late PH was associated with increased mortality, a prolonged duration of stay and higher healthcare cost.

Keywords: bronchopulmonary dysplasia; neonate; premature; pulmonary hypertension.

\section{Introduction}

The survival rates of extremely premature infants have improved significantly in the last few decades, but are associated with long term morbidities [1-3]. Bronchopulmonary dysplasia (BPD) is the most common adverse outcome and can result in complications which may extend into adulthood [4]. One of the significant contributory factors for morbidity and mortality in infants with BPD is the development of pulmonary hypertension (PH) [5].

The incidence of pulmonary hypertension in infants with BPD ranges from 17 to $37 \%$ [6-8]. The pathogenesis of pulmonary vascular disease associated with BPD is multifactorial and can be attributed to the interaction of maternal, genetic and postnatal factors. Inhibition of angiogenesis has been associated with decreased alveolarization and pulmonary vascular growth in an animal model [9]. The arrest of vascular growth and the reduction in the alveolarcapillary surface result in impaired gas exchange. Thus, the lungs are exposed to prolonged ventilation and high oxygen levels along with hemodynamic and inflammatory stressors. This causes pulmonary arterial remodelling leading to fibrosis of the vessel walls [10]. The risk factors associated with the development of pulmonary hypertension include intrauterine growth restriction, preeclampsia, maternal 
substance abuse, lower gestational age and birthweight, patent ductus arteriosus (PDA) requiring treatment and sepsis $[8,11-14]$.

The gold standard to diagnose pulmonary hypertension is cardiac catheterization, but this is often difficult to perform in BPD infants who may have significant vascular and haemodynamic complications [15]. Two-dimensional echocardiography, however, is a valuable tool for screening and diagnosis of $\mathrm{PH}$ in such patients [10]. Various studies have investigated the risk factors, outcomes $[5-8,11,14$, 16-21] and evolution of pulmonary hypertension in BPD infants [7, 8, 14, 19-21]. The identified risk factors include early pulmonary hypertension, postnatal steroid administration, tracheostomy and tracheitis [5, 16, 17]. Outcomes associated with PH in BPD infants include increased mortality and morbidity including a prolonged duration of invasive ventilation, increased occurrence of severe IVH and prolonged hospitalization [5, 7, 8, 14, 19-21]. Our aim was to identify, in infants with BPD, the effect of PH on health-care utilisation and the health related cost of care.

\section{Materials and methods}

\section{Study subjects}

An observational study was conducted of infants admitted to the neonatal unit at a London hospital, United Kingdom (UK) between January 2017 and December 2020. Badgernet, an electronic patient record database, was used to identify study subjects. The criteria for inclusion were (i) infants born at or prior to 32 weeks' gestation (ii) birthweight less than $1,500 \mathrm{~g}$ and (iii) development of BPD (oxygen requirement for at least 28 days from birth) [22]. Infants who died before 36 weeks of gestation, but required oxygen for at least 28 days were included in the study [23].

Infants had an echocardiogram when there was a clinical suspicion of pulmonary hypertension as evidenced by different preductal and post-ductal saturations, a persistently high oxygen requirement above $60 \%$ and/or requiring increased mean airway pressures to maintain oxygenation. Some infants had an echocardiogram for assessment of whether they had a patent ductus arteriosus (PDA). Infants whose echocardiogram reports were not available, who were admitted for short surgical procedures such as inguinal hernia and laser photocoagulation and those with major respiratory and cardiac anomalies were excluded from the study.

\section{Ethical approval}

The study was registered with the local Clinical Governance and Audit Department and did not require informed parental consent.

\section{Assessment of pulmonary hypertension}

The echocardiograms of the infants were reviewed by one author, a neonatologist trained in echocardiography and further reviewed by a paediatric cardiologist. The presence of $\mathrm{PH}$ was defined based on quantitative or qualitative assessments. Quantitative assessment included the presence of tricuspid regurgitant jet velocity (TRJV) $>3 \mathrm{~m} / \mathrm{s}$ (right ventricular systolic pressure (RVSP) $>36 \mathrm{~mm} \mathrm{Hg}$ ). In the absence of tricuspid regurgitation, qualitative assessment was used to detect $\mathrm{PH}$ using the following parameters: (i) flattened or left deviated intraventricular septum in ventricular systole (ii) right to left shunting across a patent foramen ovale, atrial septal defect, ventricular septal defect or patent ductus arteriosus, if present (iii) right ventricular hypertrophy or dysfunction [15].

\section{Definitions and risk factors}

BPD was defined as per the Jobe and Bancalari criteria [22]. Early PH was defined as $\mathrm{PH}$ diagnosed within 28 days after birth, while late $\mathrm{PH}$ diagnosed after 28 days [16]. Severe intraventricular haemorrhage was defined as Grade 3 or 4 as described by Papile [24].

The last echocardiogram during the admission was used to identify the presence of $\mathrm{PH}$ at discharge or death. Risk factors for late $\mathrm{PH}$ assessed included maternal preeclampsia, substance abuse, small for gestational age (SGA) (defined as birthweight less than 10th percentile or less than -1.28 standard deviation for gestational age [25]), positive pressure ventilation (PPV) at 28 days after birth, medically or surgically treated patent ductus arteriosus (PDA), sepsis (positive blood culture requiring intravenous antibiotics) and presence of early $\mathrm{PH}$.

\section{Outcomes}

We assessed the mortality in the cohort and the total duration of stay in the survivors. Additionally, the total cost of stay was calculated based on national average costs of neonatal unit stay. We also compared the length and cost of stay in infants whom $\mathrm{PH}$ resolved prior to discharge against the ones in whom $\mathrm{PH}$ did not resolve prior to death or discharge. The average daily cost ranges from $£ 437$ to $£ 1,218$ was graded based on the intensity of care coded as intensive care, high dependency and special care (Table 1) [26]. The duration of care at each level of care was extracted from Badgernet and used to estimate the total cost of stay in the neonatal unit.

\section{Statistical analysis}

On testing for normality using Shapiro-Wilk test, the data was found to be non- normally distributed. Therefore, the Mann-Whitney U test was used for comparing the continuous variables and Chi-square test for dichotomous variables. Multiple logistic or linear regression was used to adjust for confounding variables. All the risk factors were adjusted

Table 1: National schedule of reference costs in neonatal units in UK.

\begin{tabular}{ll}
\hline Level of intensity & $\begin{array}{l}\text { National average unit cost per day } \\
\text { (interquartile range) }\end{array}$ \\
\hline Intensive care & $f 1,218(f 959-f 1,399)$ \\
High dependency & $f 872(f 746-f 984)$ \\
Special care & $f 560(f 455-f 645)$ \\
\hline
\end{tabular}


for gestational age, birthweight $z$ score and 10 min Apgar score. The effect on mortality and duration of hospitalisation were further adjusted for gestational age and the duration of invasive ventilation. The effect of total cost of stay was further adjusted for gestational age. IBM SPSS Statistics for Windows, Version 25.0 (SPSS Inc. Chicago, IL) was used to analyse the data.

\section{Results}

A total of 428 premature infants were admitted to the neonatal unit during the study period, 211 (49.3\%) subsequently developed BPD; 189 infants were included in the analysis and 29 infants were excluded (Figure 1).

The included infants had a median (interquartile range) gestational age of 25.9 (24.9-27.7) weeks and birthweight of 769 (667-930) grams (Table 2). Twenty-one $(11.5 \%)$ infants had early PH of which six (28.5\%) subsequently developed late PH. Twenty-two (12\%) infants had late $\mathrm{PH}$. Amongst the 22 infants with late $\mathrm{PH}$, pulmonary hypertension resolved in 10 infants, four had pulmonary hypertension at discharge from neonatal care and eight died with pulmonary hypertension (Figure 2).

The characteristics of infants who developed early $\mathrm{PH}$, late $\mathrm{PH}$, both early and late and no $\mathrm{PH}$ have been detailed in Table 3. The infants who developed both early and late $\mathrm{PH}$ had a lower (median) gestational age (24.4 weeks) compared to those who had only early $\mathrm{PH}$ (25.7 weeks), late PH (24.6 weeks) or no PH (26.1 weeks, p=0.02). Furthermore, infants who developed both early and late $\mathrm{PH}$ had a lower (median) birthweight (603 g) compared to those who had early PH (780 g), late PH (673 g) or no PH (818 g, $\mathrm{p}<0.001$ ).

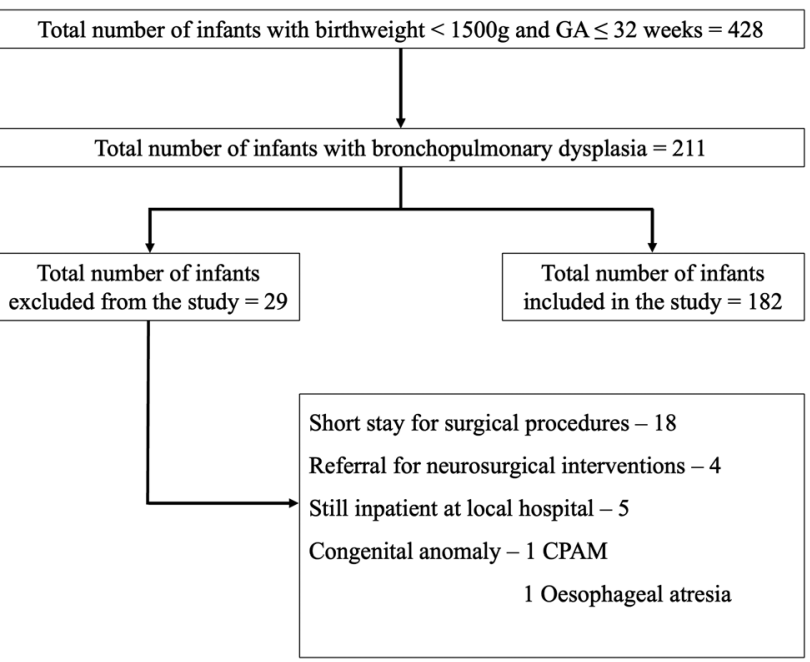

Figure 1: Flowchart of selected cases.
Table 2: Demographics of the study population.

\begin{tabular}{|c|c|c|}
\hline & $\begin{array}{r}\text { Median } \\
\text { (interquartile } \\
\text { range) }\end{array}$ & n (\%) \\
\hline Gestational age & $\begin{array}{r}25.9 \\
(24.9-27.7)\end{array}$ & \\
\hline Birthweight & 769 (667-930) & \\
\hline Small for gestational age & & $36(19.8)$ \\
\hline Sex & & Male: 94 (51.6) \\
\hline Ethnicity (maternal) & & $\begin{array}{l}\text { White: } 71 \text { (39) } \\
\text { Black: } 64 \text { (35.2) } \\
\text { Asian: } 14 \text { (7.7) } \\
\text { Mixed: } 3(1.6) \\
\text { Other: } 7 \text { (3.8) }\end{array}$ \\
\hline Mode of delivery & & $\begin{array}{l}\text { Emergency } \\
\text { caesarean: } 75 \text { (41.2) } \\
\text { Elective caesarean: } 6 \\
\text { (3.3) } \\
\text { Spontaneous vaginal: } \\
97 \text { (53.3) } \\
\text { Instrumental: } 4 \text { (2.2) }\end{array}$ \\
\hline $\begin{array}{l}\text { Antenatal steroids (at least } \\
\text { one dose) }\end{array}$ & & $169(92.9)$ \\
\hline Pre-eclampsia & & $30(16.5)$ \\
\hline Maternal substance abuse & & $4(2.2)$ \\
\hline Clinical chorioamnionitis & & $9(4.9)$ \\
\hline Early $\mathrm{PH}$ & & $21(11.5)$ \\
\hline Late PH & & $22(12.1)$ \\
\hline $\mathrm{PH}$ at death or discharge & & $12(6.6)$ \\
\hline $\begin{array}{l}\text { Positive pressure ventila- } \\
\text { tion on day } 28\end{array}$ & & $105(57.7)$ \\
\hline Inhaled nitric oxide & & $54(29.7)$ \\
\hline Inotrope administration & & $100(54.9)$ \\
\hline PDA requiring treatment & & $73(40.1)$ \\
\hline Culture proven sepsis & & 78 (42.9) \\
\hline Surgical NEC & & $18(9.9)$ \\
\hline Severe IVH & & $44(24.2)$ \\
\hline Severe ROP & & $34(18.7)$ \\
\hline Mortality & & $11(6.0)$ \\
\hline
\end{tabular}

$\mathrm{PH}$, pulmonary hypertension; PDA, patent ductus arteriosus.

The infants who developed late $\mathrm{PH}$ had a lower gestational age (24.6 vs. 26.1 weeks, $\mathrm{p}=0.002$ ) and lower birthweight (642.5 vs. $816.5 \mathrm{~g}, \mathrm{p}<0.001)$ compared to those who did not have late $\mathrm{PH}$. The infants who developed late $\mathrm{PH}$ were more often mechanically ventilated on day 28 after birth compared to the ones who did not develop late PH [100 vs. 51.9\%, p<0.001; OR: 19.5 (CI: 2.6-148)]. The infants who developed late $\mathrm{PH}$ had a longer median duration of mechanical ventilation compared to the infants without late PH (53.5 vs. 27.5 days, $p<0.001)$ [Table 4].

Eleven infants (6\%) died in the study population. Eight had pulmonary hypertension at death, of those eight, six had developed PH within 28 days after birth (Figure 2). The presence of late $\mathrm{PH}$ was independently associated with 


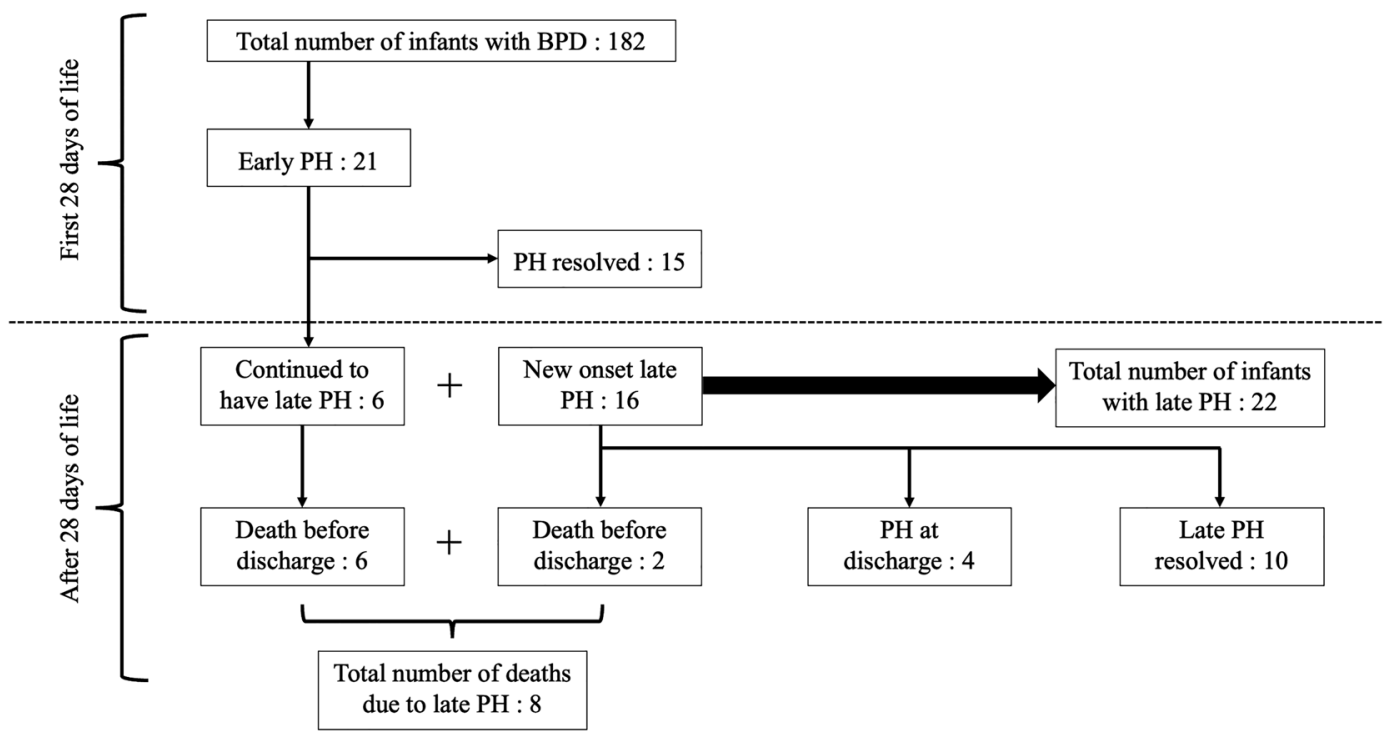

Figure 2: Development and evolution of pulmonary hypertension during neonatal stay.

Table 3: Demographics of infants by early PH, late PH, both early + late and no PH.

\begin{tabular}{|c|c|c|c|c|c|}
\hline Characteristics & $\begin{array}{r}\text { Early PH ( } n=15), n(\%) \text { or } \\
\text { median (IQR) }\end{array}$ & $\begin{array}{r}\text { Late PH }(\mathrm{n}=16), \mathrm{n}(\%) \text { or } \\
\text { median (IQR) }\end{array}$ & $\begin{array}{r}\text { Early + late PH }(n=6), n(\%) \text { or } \\
\text { median (IQR) }\end{array}$ & 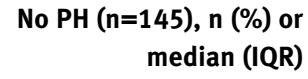 & $\begin{array}{l}\text { p- } \\
\text { Value }\end{array}$ \\
\hline $\begin{array}{l}\text { Gestational age, } \\
\text { weeks }\end{array}$ & $25.7(25.0-28.1)$ & $24.6(24.2-26.5)$ & $24.4(23.5-27.4)$ & $26.1(25-27.9)$ & 0.02 \\
\hline Birthweight, grams & $780(704-890)$ & $673(627-769)$ & $603(535-650)$ & $818(692.5-962)$ & $<0.001$ \\
\hline Birthweight $z$ scores & $-0.6(-1.2$ to 0.23$)$ & $-0.6(-1.4$ to 0.31$)$ & $-0.7(-2.5$ to 0.04$)$ & $-0.3(-1.1$ to 0.19$)$ & 0.66 \\
\hline Apgar at $10 \mathrm{~min}$ & $8(7-9)$ & $8(7-9)$ & $8(8-9)$ & $9(8-10)$ & 0.15 \\
\hline $\begin{array}{l}\text { Small for gestational } \\
\text { age }\end{array}$ & 2 (19) & $4(25.0)$ & $2(33.3)$ & $28(19.3)$ & 0.71 \\
\hline Sex, male & $8(53.3)$ & $8(50.0)$ & $4(66.7)$ & $74(51.0)$ & 0.90 \\
\hline Antenatal steroids & $13(86.7)$ & $16(100)$ & $5(83.3)$ & $135(93.1)$ & 0.40 \\
\hline Pre-eclampsia & $3(20.0)$ & $3(18.8)$ & 0 & $24(16.6)$ & 0.71 \\
\hline $\begin{array}{l}\text { Maternal substance } \\
\text { abuse }\end{array}$ & $1(6.7)$ & 0 & 0 & $3(2.1)$ & 0.59 \\
\hline
\end{tabular}

$\mathrm{PH}$, pulmonary hypertension; IQR, interquartile range.

increased mortality [OR: 21.4 (4.1-111.3), adjusted $\mathrm{p}=0.001$ ]. Similarly, the presence of late $\mathrm{PH}$ in surviving infants was independently associated with a longer duration of hospital stay [147 vs. 109 days, adjusted p: 0.03] (Table 5).

The total cost of stay for the 182 infants was $£ 17,164,290$ ( $\$ 23,957,659)$. The median (IQR) total cost of stay in infants with late PH was £113,494 (72,650-169,798) compared to $£ 78,677(48,476-115,483)$ in infants with BPD, but no late $\mathrm{PH}$ after adjusting for gestational age $(\mathrm{p}=0.016)$ [Table 5]. The median cost of stay in infants with BPD and PH was approximately £35,000 higher (44\% higher) compared to that of infants with BPD without PH.

The median length of hospitalisation was similar in infants whom PH resolved before discharge [147 (118-189) days] compared to the infants in whom PH did not resolve before discharge or died with PH [147 (72-259) days, $\mathrm{p}=0.81]$. The total cost of stay was not significantly different in infants in whom PH resolved before discharge [ $€ 85,992$ $(67,524-121,939)]$ compared to the infants in whom PH did not resolve before discharge $[€ 148,458(80,185-252,455)$, $\mathrm{p}=0.07]$.

\section{Discussion}

We have demonstrated late $\mathrm{PH}$ was associated with a higher mortality and a longer duration of stay compared to infants with BPD without PH. Furthermore, we found that the total cost of stay for infants with late PH and BPD was higher compared to those who did not develop late $\mathrm{PH}$. 
Table 4: Demographics of infants by late PH status.

\begin{tabular}{|c|c|c|c|}
\hline Characteristics & $\begin{array}{r}\text { Late PH }(\mathrm{n}=22), \\
\mathrm{n}(\%) \text { or median } \\
(\mathrm{IQR})\end{array}$ & $\begin{array}{r}\text { No late PH } \\
(n=160), n(\%) \text { or } \\
\text { median (IQR) }\end{array}$ & $\begin{array}{r}\text { p- } \\
\text { Value }\end{array}$ \\
\hline $\begin{array}{l}\text { Gestational age, } \\
\text { weeks }\end{array}$ & $\begin{array}{r}24.6(23.9- \\
26.9)\end{array}$ & $26.1(25-27.9)$ & 0.002 \\
\hline Birthweight, grams & $\begin{array}{r}642.5(610.3- \\
718.9)\end{array}$ & $\begin{array}{r}816.5(696.3- \\
960)\end{array}$ & $<0.001$ \\
\hline Birthweight $z$ scores & $\begin{array}{r}-0.6(-1.4 \text { to } \\
0.13)\end{array}$ & $\begin{array}{r}-0.34(-1.1 \text { to } \\
0.2)\end{array}$ & 0.38 \\
\hline Apgar at $10 \mathrm{~min}$ & $8(7-9)$ & $9(8-10)$ & 0.084 \\
\hline $\begin{array}{l}\text { Small for gestational } \\
\text { age }\end{array}$ & $6(27.2)$ & $30(18.8)$ & 0.35 \\
\hline Sex, male & $12(54.5)$ & $82(51.2)$ & 0.77 \\
\hline Antenatal steroids & $21(95.5)$ & $148(92.5)$ & 0.61 \\
\hline Pre-eclampsia & $3(13.6)$ & 27 (16.9) & 0.70 \\
\hline $\begin{array}{l}\text { Maternal substance } \\
\text { abuse }\end{array}$ & 0 & $4(2.5)$ & 0.45 \\
\hline $\begin{array}{l}\text { Positive pressure } \\
\text { ventilation on day } 28\end{array}$ & $22(100)$ & $83(51.9)$ & $<0.001$ \\
\hline $\begin{array}{l}\text { PDA requiring treat- } \\
\text { ment (medical/ } \\
\text { surgical) }\end{array}$ & $12(54.5)$ & $61(38.1)$ & 0.141 \\
\hline $\begin{array}{l}\text { Duration of invasive } \\
\text { ventilation, days }\end{array}$ & $53.5(42-65.8)$ & $27.5(8-48)$ & $<0.001$ \\
\hline Culture proven sepsis & $13(59.1)$ & $65(40.6)$ & 0.08 \\
\hline Presence of early PH & $6(27.3)$ & $15(9.4)$ & 0.19 \\
\hline Surgical NEC & $2(9.1)$ & $16(10)$ & 0.89 \\
\hline Severe IVH & $6(27.3)$ & $38(23.8)$ & 0.72 \\
\hline
\end{tabular}

$\mathrm{PH}$, pulmonary hypertension; IQR, interquartile range; PDA, patent ductus arteriosus.

Our study showed that while the incidence of overall mortality was $6 \%$ in the study population, the presence of late $\mathrm{PH}$ was associated with a $36 \%$ increase in mortality. Studies have described the association of $\mathrm{PH}$ and mortality with an incidence ranging from 10 to $38 \%[7,8,14,17,18,27]$. Notably, among the eight infants who died with pulmonary hypertension, six of them had developed $\mathrm{PH}$ within 28 days (Figure 2). Two studies have shown that early PH increases the risk for severe $\mathrm{BPD}$ and development of late $\mathrm{PH}$ in infants with BPD, but did not describe the impact of this on mortality $[16,17]$. This highlights the need for early as well as regular screening for pulmonary hypertension via echocardiographic assessment in infants with BPD.

One study reported the healthcare utilization of infants with PH associated with BPD presenting after two months of age into a BPD clinic and found that the infants were hospitalised for a longer duration and had more respiratory morbidity than infants with BPD but no PH [28]. Our study reported on the total cost of stay based on national average in infants with BPD and PH and to our knowledge this is the first study which specifically looked into the effect of pulmonary hypertension in infants with bronchopulmonary dysplasia on health care costs.

Our study has strengths and some limitations. In our study population we used echocardiography to identify pulmonary hypertension; echocardiography is considered to be an effective and reliable screening tool for detection of pulmonary hypertension in infants with BPD [29]. A limitation, however, was that the infants had echocardiograms at various time intervals according to clinical need rather than at specific intervals, but this makes our results generalisable to clinical practice.

In conclusion, infants with late $\mathrm{PH}$ had a longer duration of hospitalization and increased mortality compared to the infants without late $\mathrm{PH}$. The presence of late $\mathrm{PH}$ in infants with $\mathrm{BPD}$ resulted in increased healthcare costs.

Research funding: The research was supported by the National Institute for Health Research (NIHR) Biomedical Research Centre based at Guy's and St Thomas' NHS Foundation Trust and King's College London. The views expressed are those of the authors and not necessarily those of the NHS, the NIHR or the Department of Health.

Author contributions: All authors were involved in the conception of the study. FA-T, MN and AB were involved in the data collection. FA-T, TD and AG were involved in the

Table 5: Late PH and mortality and total cost of stay.

\begin{tabular}{|c|c|c|c|c|c|c|}
\hline & $\begin{array}{l}\text { Late PH ( }(n=22), n(\%) \text { or } \\
\text { median (IQR) }\end{array}$ & $\begin{array}{l}\text { No late PH }(n=160), n(\%) \text { or } \\
\text { median (IQR) }\end{array}$ & $\begin{array}{l}\text { p- } \\
\text { Value }\end{array}$ & $\begin{array}{r}\text { Odds ratio } \\
(95 \% \mathrm{Cl})\end{array}$ & $\begin{array}{r}\text { Adjusted } \\
\text { p-value }\end{array}$ & $\begin{array}{r}\text { Adjusted OR } \\
(95 \% \mathrm{Cl})\end{array}$ \\
\hline Mortality & $8(36.4)$ & $3(1.9)$ & $<0.001$ & $\begin{array}{r}29.9 \\
(7.1-125.6)\end{array}$ & 0.001 & $\begin{array}{r}26.9 \\
(3.8-189.4)\end{array}$ \\
\hline $\begin{array}{l}\text { Length of hospital- } \\
\text { isation, days }\end{array}$ & $147(118-189)$ & $109(85-149)$ & 0.002 & & 0.034 & \\
\hline $\begin{array}{l}\text { Total cost of hospital } \\
\text { stay }\end{array}$ & $\begin{array}{l}f 113,494 \\
(72,650-169,798)\end{array}$ & $\begin{array}{l}f 78,677 \\
(48,476-115,483)\end{array}$ & 0.018 & & 0.016 & \\
\hline
\end{tabular}

$\mathrm{PH}$, pulmonary hypertension; IQR, interquartile range. 
analysis of the data. All authors were involved in the preparation of the manuscript and approved the final version.

Competing interests: Authors state no conflict of interest. Informed consent: Not applicable.

Ethical approval: The study was registered with the King's College Hospital NHS Foundation Trust Clinical Governance and Audit Department and did not require informed parental consent.

\section{References}

1. Santhakumaran S, Statnikov Y, Gray D, Battersby C, Ashby D, Modi N. Survival of very preterm infants admitted to neonatal care in England 2008-2014: time trends and regional variation. Arch Dis Child Fetal Neonatal Ed 2018;103:F208-15.

2. Stoll BJ, Hansen NI, Bell EF, Walsh MC, Carlo WA, Shankaran S, et al. Trends in care practices, morbidity, and mortality of extremely preterm neonates, 1993-2012. J Am Med Assoc 2015; 314:1039.

3. Siffel C, Kistler KD, Lewis JFM, Sarda SP. Global incidence of bronchopulmonary dysplasia among extremely preterm infants: a systematic literature review. J Matern Fetal Neonatal Med 2021; 34:1721-31.

4. Zivanovic S, Peacock J, Alcazar-Paris M, Lo JW, Lunt A, Marlow N, et al. Late outcomes of a randomized trial of high-frequency oscillation in neonates. N Engl J Med 2014;370:1121-30.

5. Altit G, Bhombal S, Hopper RK, Tacy TA, Feinstein J. Death or resolution: the "natural history" of pulmonary hypertension in bronchopulmonary dysplasia. J Perinatol 2019;39:415-25.

6. Al-Ghanem G, Shah P, Thomas S, Banfield L, El Helou S, Fusch C, et al. Bronchopulmonary dysplasia and pulmonary hypertension: a meta-analysis. J Perinatol 2017;37:414-9.

7. Bhat R, Salas AA, Foster C, Carlo WA, Ambalavanan N. Prospective analysis of pulmonary hypertension in extremely low birth weight infants. Pediatrics 2012;129:e682-9.

8. Slaughter JL, Pakrashi T, Jones DE, South AP, Shah TA. Echocardiographic detection of pulmonary hypertension in extremely low birth weight infants with bronchopulmonary dysplasia requiring prolonged positive pressure ventilation. J Perinatol 2011;31:635-40.

9. Jakkula M, Le Cras TD, Gebb S, Hirth KP, Tuder RM, Voelkel NF, et al. Inhibition of angiogenesis decreases alveolarization in the developing rat lung. Am J Physiol Lung Cell Mol Physiol 2000;279: L600-7.

10. Mourani PM, Abman SH. Pulmonary hypertension and vascular abnormalities in bronchopulmonary dysplasia. Clin Perinatol 2015;42:839-55.

11. Check J, Gotteiner N, Liu X, Su E, Porta N, Steinhorn R, et al. Fetal growth restriction and pulmonary hypertension in premature infants with bronchopulmonary dysplasia. J Perinatol 2013;33: 553-7.
12. Mestan KK, Check J, Minturn L, Yallapragada S, Farrow KN, Liu X, et al. Placental pathologic changes of maternal vascular underperfusion in bronchopulmonary dysplasia and pulmonary hypertension. Placenta 2014;35:570-4.

13. Hansen AR, Barnés CM, Folkman J, McElrath TF. Maternal preeclampsia predicts the development of bronchopulmonary dysplasia. J Pediatr 2010;156:532-6.

14. An HS, Bae EJ, Kim GB, Kwon BS, Beak JS, Kim EK, et al. Pulmonary hypertension in preterm infants with bronchopulmonary dysplasia. Korean Circ J 2010;40:131-6.

15. Krishnan U, Feinstein JA, Adatia I, Austin ED, Mullen MP, Hopper RK, et al. Evaluation and management of pulmonary hypertension in children with bronchopulmonary dysplasia. J Pediatr 2017;188: 24-34.

16. Sheth S, Goto L, Bhandari V, Abraham B, Mowes A. Factors associated with development of early and late pulmonary hypertension in preterm infants with bronchopulmonary dysplasia. J Perinatol 2020;40:138-48.

17. Mourani PM, Sontag MK, Younoszai A, Miller JI, Kinsella JP, Baker $C D$, et al. Early pulmonary vascular disease in preterm infants at risk for bronchopulmonary dysplasia. Am J Respir Crit Care Med 2015;191:87-95.

18. Khemani E, McElhinney DB, Rhein L, Andrade O, Lacro RV, Thomas $\mathrm{KC}$, et al. Pulmonary artery hypertension in formerly premature infants with bronchopulmonary dysplasia: clinical features and outcomes in the surfactant era. Pediatrics 2007;120:1260-9.

19. Mirza H, Ziegler J, Ford S, Padbury J, Tucker R, Laptook A. Pulmonary hypertension in preterm infants: prevalence and association with bronchopulmonary dysplasia. J Pediatr 2014; 165:909-14.

20. Del Cerro MJ, Sabaté Rotés A, Cartón A, Deiros L, Bret M, Cordeiro $M$, et al. Pulmonary hypertension in bronchopulmonary dysplasia: clinical findings, cardiovascular anomalies and outcomes. Pediatr Pulmonol 2014;49:49-59.

21. Kwon HW, Kim H-S, An HS, Kwon BS, Kim GB, Shin SH, et al. Longterm outcomes of pulmonary hypertension in preterm infants with bronchopulmonary dysplasia. Neonatology 2016;110:181-9.

22. Jobe AH, Bancalari E. Bronchopulmonary dysplasia. Am J Respir Crit Care Med 2001;163:1723-9.

23. Poindexter BB, Feng R, Schmidt B, Aschner JL, Ballard RA, Hamvas $A$, et al. Comparisons and limitations of current definitions of bronchopulmonary dysplasia for the prematurity and respiratory outcomes program. Ann Am Thorac Soc 2015;12:1822-30.

24. Papile L-A, Burstein J, Burstein R, Koffler H. Incidence and evolution of subependymal and intraventricular hemorrhage: a study of infants with birth weights less than 1,500 gm. J Pediatr 1978;92:529-34.

25. Royal College of Obstetricians and Gynaecologists (RCOG). Small-for-gestational-age fetus, investigation and management (green-top guideline no. 31). London: RCOG; 2002 (update 2013). Available from: www.rcog.org.uk/en/guidelines-researchservices/guidelines/gtg31/.

26. Department of Health: reference costs guidance 2015-2016; national schedule of reference costs - main schedule. London, UK: Department of Health and Social Care; 2016:1-59 pp. 
27. Aswani R, Hayman L, Nichols G, Luciano AA, Amankwah EK, Leshko JL, et al. Oxygen requirement as a screening tool for the detection of late pulmonary hypertension in extremely low birth weight infants. Cardiol Young 2016;26:521-7.

28. Stuart BD, Sekar P, Coulson JD, Choi SE, McGrath-Morrow SA, Collaco JM. Health-care utilization and respiratory morbidities in preterm infants with pulmonary hypertension. J Perinatol 2013; 33:543-7.

29. Nagiub M, Lee S, Guglani L. Echocardiographic assessment of pulmonary hypertension in infants with bronchopulmonary dysplasia: systematic review of literature and a proposed algorithm for assessment. Echocardiography 2015;32:819-33. 